\title{
Abordagem, método e técnica: diálogos e duelos
}

\author{
Diego Moreno Redondo \\ Pontifícia Universidade Católica (PUC), São Paulo, São Paulo, Brasil \\ dimoreno2@hotmail.com
}

DOI: http://dx.doi.org/10.21165/el.v45i2.660

\begin{abstract}
Resumo
O presente trabalho apresenta, como eixo central, a análise da concepção de método de cinco professores-coordenadores de cursos de inglês, em cinco institutos privados de idiomas de uma cidade do interior paulista. Com base na teoria sobre método já estabelecida por Anthony (1963), este estudo analisa a concepção de método desses participantes da pesquisa, uma vez que, no contexto dos institutos de idiomas, esses profissionais representam a ideologia da instituição na qual trabalham e, por isso, são responsáveis pela realização de cursos de formação para todos os professores a fim de preparar esses profissionais para ministrar as aulas com base no método utilizado pelo instituto. Além disso, é possível investigar até que ponto os termos abordagem, método e técnica são usados como sinônimos ou com um sentido diferente do estabelecido por Anthony (1963).
\end{abstract}

Palavras-chave: abordagem; método; técnica; ensino-aprendizagem de inglês.

\section{Approach, Method and Technique: Dialogues and Duels}

\begin{abstract}
The centerpiece of this work covers the method conception analysis of five Teacher Coordinators of English courses in five private language institutes of a city in São Paulo State. Based on the theory about method already established by Anthony (1963), this study examines the method conception of these participants, once, in the context of the language institutes, these professionals represent the ideology of the institution where they work and, therefore, are responsible for conducting training courses for all teachers in order to prepare these professionals for teaching classes based on the method used by the institute. Furthermore, it is possible to investigate the extent to which the terms approach, method and technique are used as synonymous or with a different meaning from that established by Anthony (1963).
\end{abstract}

Keywords: approach; method; technique; English learning and teaching.

\section{Introdução}

No contexto atual, a oferta de cursos de inglês em institutos privados de idiomas cresce desenfreadamente. Frente a essa grande implosão de cursos voltados ao ensino de língua inglesa, surge o interesse pela análise do ponto de vista de coordenadores de institutos privados de idiomas sobre os conceitos de método.

Diante de uma sociedade movida pelo rápido avanço tecnológico, a profusão de informações e o pluralismo cultural, os institutos privados de idiomas veem-se obrigados a repensar as metodologias usadas no ensino de línguas para conseguirem atingir um novo público. Sendo assim, muitos profissionais da área de ensino de línguas 
têm adotado, adaptado, inventado e desenvolvido uma variedade de termos e estratégias, designados por eles como métodos, que descrevem as atividades nas quais eles estão envolvidos para desenvolver o seu trabalho, pois, como professores-coordenadores, além de ministrar aulas, também são responsáveis pela orientação do grupo de professores de acordo com o plano de ensino do instituto que cada um deles representa, oferecendo cursos de formação para que os professores conheçam as propostas de ensino e, com isso, possam trabalhar, tomando-as como base para ensinar a língua inglesa.

É comum encontrar em trabalhos acadêmicos e, principalmente, em sites de institutos de idiomas os termos abordagem, método e técnica sendo utilizados de forma equivocada e, muitas vezes, como sinônimos. Segundo Anthony (1963), é preciso esclarecer essa confusão terminológica para que as pesquisas na área de Linguística Aplicada, especialmente, no campo da pedagogia do ensino de línguas, não sejam prejudicadas e possam avançar. Além disso, a partir do momento em que o professor conhece não só a conceituação dos termos abordagem, método e técnica, mas, principalmente, a função de cada um deles, consegue apoiar-se nas teorias que sustentam cada abordagem, organizando e planejando a sua prática por meio dos métodos e técnicas mais adequadas a cada situação de ensino-aprendizagem.

Pautado na justificativa já apresentada, este artigo tem como intuito apresentar o que cinco professores-coordenadores de institutos privados de idiomas, representados neste trabalho pelas siglas PC-1, PC-2, PC-3, PC-4 e PC-5, entendem por abordagem, método e técnica. Por outro lado, será possível, também, esclarecer a confusão terminológica que envolve esses termos e perceber em que momento esses termos dialogam ou duelam, uma vez que, segundo Anthony (1963), o método é o estágio intermediário entre a abordagem de ensino e a técnica utilizada pelo professor. Por abordagem, ele compreende a noção do professor sobre a natureza da linguagem e dos processos de ensino-aprendizagem. Cabe ao método o papel de plano geral para a apresentação e ensino da língua, ou seja, as etapas ou o passo a passo de como será realizado o ensino. Por fim, tendo sido planejado o método, esse é realizado na prática docente por diferentes técnicas.

Para apresentar os resultados alcançados com esta pesquisa, este trabalho dividese da seguinte maneira: em um primeiro momento, apresento a metodologia da pesquisa; na sequência, exponho a formação dos participantes; em seguida, discuto a concepção de abordagem dos participantes; logo a seguir, descrevo o que eles compreendem por método e, na sequência, analiso a concepção de técnica de cada professor-coordenador.

Por fim, na seção sobre as considerações finais, apresento minhas percepções acerca da temática apresentada por esta pesquisa, tomando como base a definição de Anthony (1963) a respeito dos termos abordagem, método e técnica.

\section{Metodologia da pesquisa}

A partir do objetivo principal da pesquisa em questão: analisar a concepção de método utilizada por professores-coordenadores de institutos privados de idiomas, optei por utilizar como estratégia de pesquisa o estudo de caso, de acordo com Stake (1998). Segundo Stake (1998, p. 86), “o estudo de caso não é uma escolha metodológica, mas 
sim, uma escolha do objeto a ser estudado. Portanto, escolhe-se estudar um determinado caso em sua particularidade".

Stake (1998) classifica o estudo de caso em três tipos: intrínseco, instrumental e coletivo. Com base nessa classificação, posso afirmar que este trabalho apoia-se no estudo de caso do tipo coletivo e instrumental: coletivo porque participam desta pesquisa cinco institutos privados de idiomas, representados por seus professorescoordenadores, em seus reais contextos de trabalho; instrumental porque a pesquisa tem como objetivo compreender melhor um determinado assunto, isto é, a concepção de método dos participantes.

A coleta de dados foi realizada por meio de instrumentos típicos do paradigma qualitativo. Iniciou-se a coleta utilizando a entrevista escrita, uma vez que os participantes não aceitaram participar de uma entrevista oral. A entrevista escrita era composta por um questionário com dezesseis questões dissertativas, pois, segundo Nunan (1995), em perguntas abertas, o participante tem a liberdade para decidir o que e como responder. No decorrer da coleta, foi necessário utilizar mais um instrumento, ou seja, o e-mail dialogado. Atribuo ao e-mail o adjetivo dialogado porque conforme enviava as dúvidas para os participantes, eles me retornavam com esclarecimentos. Isso significa que o e-mail funcionou como um diálogo virtual.

\section{A formação dos professores-coordenadores}

Ao tratar de qualquer área da ciência, pressupõe-se que todo profissional envolvido em um campo específico do conhecimento tenha no mínimo uma formação adequada para assumir tal função. Não é o que acontece com alguns profissionais que podemos encontrar nos institutos privados de idiomas.

Para evidenciar ainda mais esse fato, destaco a formação acadêmica dos participantes: o PC-1 possui formação técnica em processamento de dados, o PC-2 é formado em Letras-Inglês, Engenharia Civil e Matemática, o PC-3 é graduado em Letras-Italiano, o PC-4 é graduado em Cinema e o PC-5 é formado em Letras-Inglês.

Diante dessa informação, constata-se que os institutos privados de idiomas que compõem esta pesquisa não exigem de professores e coordenadores uma formação acadêmica em área específica, o importante é o profissional dominar a língua a ser ensinada.

Frente a essa problemática, é difícil, no contexto desta pesquisa, os profissionais conseguirem resolver problemas que envolvem suas práticas não tendo uma formação sólida que sustente o ensino-aprendizagem da língua a qual ensinam. Segundo Leffa (1999), apesar de desempenhar também um papel político e social, o docente tem seu foco no processo de ensino-aprendizagem e, para lidar com a diversidade de indivíduos que constituem um contexto específico, o docente deverá possuir não apenas o domínio específico da área, mas também o domínio das áreas pedagógicas e o desenvolvimento das habilidades essenciais para o exercício docente.

A questão é: como esses profissionais apropriam-se de conceitos de ensinoaprendizagem de língua estrangeira e lidam com isso sem ao menos possuírem uma formação que lhes dê autonomia para discutir esses assuntos com a equipe gestora, os coordenadores e os professores? Não é possível tratar de aspectos pedagógicos e metodológicos sem uma bagagem no mínimo satisfatória para abarcar as questões sobre 
ensino-aprendizagem que, consequentemente, surgem nesse ambiente de trabalho no decorrer do curso e, principalmente, na organização e planejamento do currículo que rege o ensino em institutos privados de idiomas. Uma formação consistente é o caminho para tornar o professor maduro, crítico e seguro para desenvolver bem o seu papel.

\section{A concepção de abordagem dos participantes}

Em 1963, Anthony publica o artigo Approach, method and technique, no qual o autor define que a abordagem é a concepção de linguagem e de ensino-aprendizagem do professor.

Com base nessa teoria acerca da concepção de abordagem apresentada pelo teórico que dá sustentação a essa pesquisa, disponho-me, neste momento, a exemplificar as concepções de abordagem dos participantes deste estudo. Os professorescoordenadores que fazem parte desta pesquisa expuseram a opinião deles em torno do conceito de abordagem. Para obter informações dos participantes sobre o que eles compreendem por abordagem, elaborei a seguinte questão: $\mathrm{O}$ que você compreende por abordagem? Explique. Dê exemplos.

As respostas dos participantes a essa pergunta seguem abaixo, obedecendo a seguinte ordem: PC-1, PC-2, PC-3, PC-4 e PC-5, sendo que a fala de cada professorcoordenador é seguida por uma análise acerca da concepção de abordagem apresentada por cada um deles.

Observe a concepção de abordagem, segundo o PC-1:

PC-1: É a forma de passar a informação para o aluno. Forma de transmitir algo à alguém. Quando você quer comunicar algo, investigar qual é a melhor forma de realizar a comunicação. Exemplo: Dar instruções = mensagem. Abordagem = meu interlocutor us a qual sentido para perceber o mundo? Se ele usar a visão, por exemplo, transmitir as instruções de forma que ele possa 'ver' o que você está dizendo, por meio de um desenho ou mostrando-lhe.

O PC-1 afirma que a abordagem refere-se ao modo como a informação é transmitida ao aluno e, também, a forma de transmitir algo a alguém. Essa conceituação revela claramente a noção do professor de que a condução da aula, a maneira como a aula é realizada, enfim, todo o planejamento realizado pelo professor para realizar o ensino, é entendido por ele como abordagem. $\mathrm{Na}$ frase do $\mathrm{PC}-1$, percebe-se que ele atribui à abordagem o significado de método, uma vez que toda a organização das aulas, os passos a serem seguidos para executá-las estão a cargo do método utilizado.

Para o PC-1, a abordagem está relacionada à maneira como a informação é transmitida ao aluno, enquanto para o PC-2, a abordagem assume outra função. Veja abaixo:

PC-2: A abordagem é o por que, como fazer com que o aluno se interesse sobre o as sunto. O que pode motivá-lo a estudar. Como podemos ativar as inteligências dos alunos para que eles aprendam. As atividades devem ter vários tópicos como, por exemplo: discussões, diálogos, escritos e falados, apresentações, leitura e etc. Assim podemos ativar várias das inteligências e enfatizarmos a abordagem comunicativa.

Para o PC-2, a abordagem está relacionada à motivação dos alunos, ou seja, o que pode ser feito para que o aluno se interesse pelas aulas. Com certeza uma aula que 
leve o aluno a se interessar pelo que é ensinado pode estar relacionada à abordagem seguida pelo instituto, mas o papel de planejar as aulas e a interação entre professoraluno, com o objetivo de provocar o interesse dos alunos, não é competência da abordagem. Nesse caso, a abordagem é o pano de fundo que sustenta tal método, ou seja, a partir de uma concepção do professor de como a língua deve ser ensinada, o método deve dar conta da elaboração das aulas e de como essas aulas podem despertar o interesse dos alunos. Sendo assim, a concepção de abordagem do PC-2 confunde-se com o significado de método.

O significado de abordagem para o PC-3, apesar de não estar muito detalhado, estabelece uma conexão com a definição de Anthony (1963), ou seja, a abordagem vista como a concepção de linguagem e de ensino-aprendizagem do professor. Isso fica claro no excerto que segue:

PC-3: Abordagem é como se acredita que a língua deve ser ensinada. Um curso com abordagem comunicativa prepara o aluno para se comunicar em diversas situações culturais e sociais.

A concepção de abordagem do PC-3 está muito próxima da conceituação estabelecida por Anthony (1963), apresentando a noção clara de que a abordagem é como se acredita que a língua deve ser ensinada, isto é, a compreensão do professor sobre o ensino-aprendizagem de uma língua.

O PC-4 apresenta uma concepção de abordagem que foge às concepções já apresentadas. Observe no trecho seguinte:

PC-4: Uma forma de aproximação, forma de tratar alguma questão. Como o professor se comporta diante dos alunos e como os alunos são abordados para aprender a língua. Uma forma de se relacionar com os alunos.

O professor-coordenador 4 apresenta uma significação de abordagem bem diferente do que vimos até o momento. Segundo o PC-4, a abordagem é derivada do verbo 'abordar', ou seja, a maneira como o professor chega até o aluno para ensinar uma língua. Essa conceituação foge extremamente do conceito de abordagem usado nesta pesquisa, mas o interessante é que, ao analisar a fala completa do professorcoordenador 4, percebe-se uma aproximação com a noção de método, pois como o professor conduzirá as aulas e a maneira escolhida para tratar determinadas questões para conseguir interagir com os alunos podem ser pensados antes e durante a execução do método seguido pelo professor durante as aulas. $\mathrm{O}$ que fica claro na concepção do PC-4 é que toda a organização de como as aulas serão ministradas ele define como abordagem, mas na verdade faz parte do método.

A última análise sobre a concepção de abordagem concentra-se na fala do PC-5. Para esse professor-coordenador, a abordagem possui um papel filosófico dentro do ensino-aprendizagem de língua estrangeira. Entenda o que significa a filosofia mencionada por ele nas falas abaixo:

PC-5: Embora esses três termos sejam muitas vezes usados uns pelos outros na literatura, eu definiria "abordagem" como os pressupostos gerais que descrevem uma determinada teoria, ex: a abordagem comunicativa. Resumindo, a filosofia (abordagem) determina os métodos (sequências de estágios), que são realizados através de atividades específicas (técnicas). 
A compreensão do PC-5 sobre abordagem representa a tríade estabelecida por Anthony (1963). Quando o participante diz: "Embora esses três termos sejam muitas vezes usados uns pelos outros na literatura" está referindo-se aos termos abordagem, método e técnica. Segundo o professor-coordenador 5, a abordagem é a concepção filosófica que norteia o ensino realizado pelo professor. $O$ que fica evidente na passagem seguinte, na qual o PC-5 esclarece a noção de filosofia citada no excerto referente à sua concepção de abordagem:

PC-5: Quando digo a filosofia quero dizer a ideia mesmo que o professor tem de como deve ensinar a língua. O que está por trás da maneira como aquele professor ensina.

A fala do PC-5 complementa a concepção já exposta anteriormente, cujo conceito relaciona-se à concepção de ensino-aprendizagem. Essa noção de abordagem também segue a conceituação proposta por Anthony (1963).

Os excertos apresentados anteriormente mostram o que os professorescoordenadores compreendem por abordagem. Em suma, conclui-se que, com exceção do PC-3 e PC-5, fica evidente que, por mais divergentes que sejam as concepções, todas elas gravitam em torno da concepção de método. O PC-1, PC-2 e PC-4 utilizam o termo abordagem como sinônimo de método ao atribuir a ela o papel de organizar, planejar e estruturar o ensino-aprendizagem de uma língua. Cabe à abordagem a função de nortear e embasar o método utilizado nas aulas. Sendo assim, tomando como referência os princípios que regem tal abordagem, far-se-á a organização e estruturação de cursos e/ou aulas, levando em consideração cada contexto de ensino.

\section{A concepção de método dos participantes}

Para analisar a concepção de método dos participantes, apoio-me na conceituação de método estabelecida por Anthony (1963). À guisa de apoio e ênfase, vale recordar que, segundo o teórico, o método é o estágio intermediário entre a abordagem e a técnica, sendo responsável pelo planejamento do processo realizado em um contexto de ensino-aprendizagem de línguas. Ainda a esse respeito, o teórico enfatiza que todo método deve ter como base uma abordagem e pode ser realizado na prática por diferentes técnicas.

Essa concepção de método não é recente, porém persistiu por muito tempo e até hoje é utilizada por diferentes pesquisadores como, por exemplo: Almeida Filho (2013), Borges (2010) etc. Esse foi um dos motivos que justificaram a minha escolha pelo uso desse artigo para embasar esta pesquisa, além de considerá-lo um bom exemplo conceitual dos termos abordagem, método e técnica ao que concerne o ensinoaprendizagem de línguas.

Em busca de respostas sobre o que os professores-coordenadores pensam sobre método, lancei mão de algumas perguntas que contemplavam a concepção de método desses participantes.

Agora, apresento detalhadamente a compreensão de método presente nas falas dos professores-coordenadores, obedecendo a seguinte ordem: PC-1, PC-2, PC-3, PC-4 e PC-5:

Para o PC-1, o método é: 
PC-1: O objetivo a ser alcançado precisa de planejamento e um plano de ação que, por sua vez, requer um método a ser utilizado. Exemplo: objetivo = alunos cumprimentarem-se em inglês, método = intuitivo visual? Neste caso pode-se usar gestos, imagens; intuitivo sinestésico? Neste caso podese usar gestos como apertar as mãos em cumprimento.

O PC-1 atribui ao método a função de organizar e planejar uma determinada ação. Quanto a dizer que o método é responsável pelo planejamento da ação, chamo a atenção para esclarecer que o método é o próprio planejamento das etapas a serem seguidas na execução de uma aula, ou seja, o plano de ação não requer um método, ele é o próprio método. Ao definir como as aulas serão ministradas, as técnicas que serão utilizadas e a sequência das aulas tem-se a visão do método.

Além dessa visão, chamo a atenção para outro equívoco: no momento em que troca o termo abordagem por método ao dizer "método = intuitivo visual". Ao se referir à abordagem intuitiva ${ }^{1}$ como método revela que o conceito de método ainda não está tão claro. Essa confusão entre o conceito de método e de abordagem também ocorre na seguinte passagem:

PC-1: a metodologia comunicativa aliada a estrutura e aos recursos permite que o aluno aprenda através de representações de situações que vivemos na vida social.

No excerto acima, o termo metodologia é usado de forma equivocada. Nesse contexto, de acordo com a conceituação de abordagem, método e técnica definida por Anthony (1963), o termo adequado é abordagem comunicativa e não metodologia comunicativa como afirma o PC-1, já que a expressão utilizada por ele refere-se à concepção de como a língua deve ser ensinada e não ao método adotado para ensiná-la. Nessa frase, pode-se perceber também uma confusão em relação ao termo metodologia e método. Por essa razão, vale ressaltar a diferença entre esses dois termos, uma vez que são usados várias vezes como sinônimos, o que justifica a necessidade de distingui-los.

O método já foi aqui definido e o termo metodologia possui um significado muito próximo ao conceito de abordagem, mas são essencialmente diferentes, conforme constata Borges (2010):

[...] a metodologia é essencialmente baseada na experiência construída em sala de aula. Isso equivale a dizer que os termos abordagem e metodologia compartilham significados, mas a abordagem é fruto das reflexões de teorizadores (das comunidades científicas), ao passo que a metodologia é o resultado direto do que o professoreducador definitivamente realiza em contextos reais de ensino-aprendizagem, lançando mão ou não (implícita ou explicitamente) da visão dos teorizadores. (BORGES, 2010, p. 404).

Diante da citação apresentada e a compreensão do PC-1 sobre o método, é possível que tal confusão entre os termos metodologia e abordagem seja decorrente da semelhança entre os significados apontados por Borges (2010). Porém, ainda sobre essa questão, é preciso destacar que, segundo Holmes (2000), o termo metodologia suscita diversas discussões no campo de ensino de línguas devido à abrangência conceitual que muitos teóricos concedem ao termo.

\footnotetext{
1 Segundo Celce-Murcia (1991), a Abordagem Intuitiva-imitativa consiste em fazer com que o aluno seja capaz de identificar sons/ritmos produzidos por modelos teoricamente eficazes (o professor e/ou o gravador) e reproduzi-los o mais fielmente possível, sem intervenções explícitas de informações técnicas.
} 
Trago essa discussão em um momento que dedico à análise da concepção de método dos participantes desta pesquisa porque pude perceber que, em algumas situações, o termo metodologia confunde-se com método ou com abordagem, conforme ficou constatado na fala do PC-1. É importante esclarecer a diferença entre esses termos para que o uso não se torne banalizado a ponto de serem usados um pelo outro por falta de discernimento entre o significado de cada termo.

Dando sequência à análise, abaixo segue a concepção de método do PC-2:

PC-2: O método é a teoria que estabelece o relacionamento entre professor/aluno/material no processo de aprendizagem. O método que a escola encontra para que sua abordagem e metodologia deem certo é treinar os professores continuamente, utilizar-se de recursos audiovisuais, escritos, de leitura e principalmente de comunicação.

Para o PC-2, o método é a teoria que estabelece a relação entre professor-alunomaterial no processo de aprendizagem. Não há dúvida que o método pode proporcionar uma aproximação entre esses três protagonistas no ensino-aprendizagem, mas o método não é uma teoria. Ao se referir ao método como uma teoria, o PC-2 quis fazer referência à abordagem, porém não percebeu a confusão entre os termos, usando o termo método com o sentido de abordagem. Isso fica claro no trecho que segue:

PC-2: eu disse que o método é uma teoria porque é ele que decide o que vamos fazer na prática. Seguimos um método de ensino para dar as aulas e ele é res ponsável pela maneira como as aulas são dadas.

Além dessa confusão terminológica, o PC-2 afirma que "o método que a escola encontra para que sua abordagem e metodologia deem certo é treinar os professores continuamente".

No excerto correspondente à concepção de método do PC-2, ficou evidente a dificuldade em diferenciar um termo do outro a ponto de usá-los com o mesmo significado. Além disso, a palavra metodologia também aparece com o sentido de método e ao mesmo tempo de abordagem, assim como na concepção do PC-1. Note que a fala do PC-2, no primeiro excerto, apresenta duas interpretações: a primeira está ligada ao termo método: "o método é a teoria que estabelece a relação entre professoraluno-material no processo de aprendizagem". Nesse caso, a palavra método está referindo-se à abordagem, como se comprova no pensamento apresentado por ele, no segundo excerto: "eu disse que o método é uma teoria porque é ele que decide o que vamos fazer na prática"; a segunda interpretação refere-se ao termo metodologia que pode estar referindo-se ao método quando, no primeiro excerto, o PC-2 afirma que "o método que a escola encontra para que sua abordagem e metodologia deem certo é treinar os professores continuamente".

O PC-3 atribui ao método o sentido de procedimento. Observe no trecho que segue:

PC-3: É o procedimento adotado para o ensino tendo certa abordagem em mente. O método distribui a matéria pelo curso todo e nos dá uma visão global do curso. Ele vai variar de acordo com faixa etária, por exemplo.

Para o PC-3, o método equivale ao procedimento. No momento em que o professor-coordenador 3 afirma que o método distribui a matéria pelo curso, dando-nos 
uma visão global desse curso, a concepção de método está muito restrita à distribuição do conteúdo ao longo de um curso.

$\mathrm{Na}$ verdade, essa distribuição citada pelo PC-3 é consequência do método, mas não função dele. Segundo Anthony (1963), cabe ao método apresentar de maneira ordenada o material de linguagem, já que ele tem a função de pôr em prática o ensino de um determinado material linguístico (língua/linguagem), baseando-se em uma abordagem.

A meu ver, o problema da concepção do PC-3 está na escolha da palavra procedimento. É preciso tomar cuidado ao definir o método como procedimento. Primeiro é preciso ter consciência da teoria na qual se apoia para utilizar esse termo. Isso porque a palavra procedimento aparece com diferentes significados na literatura de ensino de línguas.

Segundo Richards et al. (2001), o termo procedimento está relacionado às técnicas realizadas em sala de aula. Para Anthony (1963), o termo procedimento também está relacionado à técnica, enquanto para Almeida Filho (2013), esse termo faz parte do método: "como método contam os procedimentos construtores das aulas e extensões delas" (ALMEIDA FILHO, 2013, p. 34). Devido a essa divergência de opiniões é preciso estar atento ao uso desse termo ao utilizá- lo para se referir ao método.

Nesse contexto, referente à concepção do PC-3, o uso do termo procedimento foi usado para conceituar o método, ou seja, para o PC-3 o método é "o procedimento adotado para o ensino tendo certa abordagem em mente". Sendo assim, a conceituação do professor-coordenador 3 foge à concepção de método de Anthony (1963) e está mais próxima à ideia de Almeida Filho (2013).

Enquanto para o PC-3 o método é um procedimento adotado ao ensinar, para o PC-4, esse termo recebe uma noção um tanto ampla. Observe a opinião do PC-4 a esse respeito:

PC-4: Forma de fazer, agir, dizer, ensinar, seguindo os princípios e ordem. Os recursos que são utilizados para ensinar o inglês. O professor usa uma variedade de instrumentos para dar aula, seguindo a metodologia estipulada pela escola como, por exemplo, o método neurolinguístico, usado aqui na nossa escola.

$\mathrm{Na}$ definição do $\mathrm{PC}-4$, podemos apontar alguns problemas quanto à concepção de método. Ao definir o que compreende por método, o professor-coordenador 4 utiliza diferentes verbos para conceituá-lo, o que demonstra uma incerteza quanto ao conceito e até mesmo a utilidade do método. Está mais próximo do conceito de método quando o PC-4 diz que seguem os princípios e ordem, pois o método tem realmente a característica de ditar a sequência das aulas, porém a maneira como o professor age, diz ou ensina tem muito mais a ver com sua prática do que especificamente com o método empregado. Contudo, afirmar que o método é a forma de agir, dizer, fazer e ensinar denota ao método uma carga significativa muito maior do que the é real, além de transmitir a ideia de que todos os professores dizem, agem, fazem ou ensinam da mesma maneira apenas por adotarem o mesmo método.

Outra questão a ser discutida é quando o PC-4 cita os recursos utilizados nas aulas como sendo um método. Essa concepção é um tanto enganosa, uma vez que o recurso deve ser entendido como um auxilio, o meio para obter um objetivo como, por exemplo: DVD, rádio, filme, música etc. Tudo isso funciona como apoio $\mathrm{e}$ 
complemento de uma determinada aula a fim de alcançar um objetivo já préestabelecido pelo método que orienta a sequência de ação dessa aula. Além disso, mais uma vez aparece o termo metodologia com o sentido de método, como se pode notar na fala do PC-4: "o professor usa uma variedade de instrumentos para dar aula, seguindo a metodologia estipulada pela escola como, por exemplo, o método neurolinguístico, usado aqui na nossa escola". Nessa citação, fica evidente que o PC-4 cita o método neurolinguístico, termo usado por ele, como exemplo da metodologia usada pela escola, ou seja, os dois termos sendo usados como sinônimos mais uma vez entre os professores-coordenadores dos institutos de idiomas que fazem parte desta pesquisa. Esse fato só comprova que não há só confusão entre os termos abordagem, método e técnica, mas começam a aparecer outros termos, tais como recurso e metodologia também de maneira equivocada.

A próxima fala analisada refere-se à concepção de método do PC-5. Observe que o conceito de método estabelecido pelo PC-5 tem muita relação com a proposta de Anthony (1963):

PC-5: O "método" seria a sequência de passos utilizada para se ensinar, sequência essa determinada pela abordagem seguida (ex. o paradigma presentation-practice-production), muito utilizado dentro da abordagem comunicativa, embora muito criticado pela questionável autenticidade de comunicação oferecida.

O último dos participantes apresenta uma concepção de método ligada à ideia exposta por Anthony (1963). Segundo o PC-5: 'O 'método' seria a sequência de passos utilizada para se ensinar, sequência essa determinada pela abordagem".

$\mathrm{O}$ interessante nessa passagem é mostrar que o PC-5 sente-se seguro ao definir o que ele compreende por método. Isso fica comprovado ao ser questionado sobre as aspas usadas no termo método.

A respeito dessa questão, o PC-5 diz que:

PC-5: preferi destacar a palavra método com aspas porque é um termo usado com diferentes sentidos em vários textos que já li sobre o assunto, por esse motivo achei melhor destacá-lo para indicar que essa é a minha opinião sobre o significado dessa palavra, claro com influência das leituras que já fiz.

Essa afirmação do PC-5 deixa claro que ele é um profissional que está atento aos assuntos da área. Dentre os cinco participantes da pesquisa, em relação à concepção de abordagem e do método, ele é o que apresenta uma noção mais ampla e aprofundada desses dois termos analisados até o momento.

Diante de concepções tão diferentes, mas ao mesmo tempo aplicadas para se referir ao método, fica claro que ainda há uma dificuldade em diferenciar tais termos a ponto de conseguir utilizá-los de maneira clara. O PC-3 apesar de ser menos preciso e detalhista também deixou claro que conhece os termos abordagem e método dos quais faz uso no cotidiano profissional. O PC-5 apresenta a sua opinião de maneira mais detalhada e abrangente, enquanto os PC-1, PC-2 e PC-4 mostraram ter dificuldade em diferenciar os termos abordagem e método, contribuindo para o uso equivocado dessas terminologias na área de ensino de línguas. 


\section{A concepção de técnica dos participantes}

O conceito de técnica encontra-se alocado na terceira categoria da hierarquização estabelecida por Anthony (1963). A definição de técnica apresentada por esse teórico há cinquenta e um anos sofreu críticas e, consequentemente, no século XXI, o seu conceito e abrangência adaptam-se ao contexto atual, porém conservam a sua essência.

Segundo Anthony (1963), a técnica é a implementação, uma estratégia ou um artifício usado para que se alcance um objetivo proposto. Ela deve estar consistente com um método e, por conseguinte, de acordo com uma abordagem.

$\mathrm{Na}$ época em que Anthony (1963) escreveu o artigo Approach, method and technique, o teórico enquadra os recursos como parte integrante da técnica, fato que com o tempo foi distanciando-se dessa associação e, atualmente, conhecemos como recursos, materiais utilizados durante as aulas para complementar o ensino como, por exemplo: CDs, filmes, música, jogos etc. De acordo com Almeida Filho (2011), ocorre ao final do artigo a inclusão do que seriam hoje recursos no lugar de técnicas. Isso em nada desmerece a adiantada visão anthoniana de que precisávamos reconhecer as categorias, generalizações e relações hierárquicas no grande processo de ensino de línguas. Provavelmente, se o artigo fosse escrito hoje, o termo recurso faria parte da hierarquia clássica anthoniana. Isso porque, nos dias atuais, segundo Almeida Filho (2011), em decorrência das ações e especialmente da produção de experiências com e na nova língua, ficam previstos os vários recursos que viabilizam e intensificam as ações e as técnicas.

Para chegar ao objetivo proposto desta seção, isto é, apresentar as concepções de técnica de cada participante desta pesquisa, tomei como norte a seguinte pergunta: $\mathrm{O}$ que você compreende por técnica? Explique. Dê exemplos. A partir desta questão, baseando-se, também, nas demais perguntas do questionário foi possível chegar à concepção de técnica de cada entrevistado. Assim como os termos abordagem e método apareceram com sentidos bem divergentes, com o significado de técnica não foi diferente. É possível notar que esse termo também apresenta algumas dificuldades quanto à significação.

A fim de mostrar os diferentes significados atribuídos ao termo técnica, apresento a seguir as falas dos PC-1, PC-2, PC-3, PC-4 e PC-5, nessa respectiva ordem, nas quais é possível analisar as concepções de técnica de cada participante. Inicio com o excerto correspondente à opinião do PC-1:

PC-1: É um processo menor dentro da metodologia, um processo de sistematização. Conjunto de métodos. Para ensinar, podemos utilizar diferentes métodos, tomando como exemplo os sentidos visual, auditivo, sinestésico, usando todos ao mesmo tempo temos a técnica de ensino por meio da inteligência emocional.

O PC-1 atribui à técnica uma característica sistemática, ou seja, como se a técnica fosse um sistema dentro da metodologia. Em seguida, diz que é um conjunto de métodos. $\mathrm{Na}$ verdade, o método é realizado na prática por diferentes técnicas. Isso quer dizer que a técnica jamais é um conjunto de métodos. O que geralmente acontece é o método ser realizado por diferentes técnicas conforme já dito antes, mas o contrário não é possível. Também não ousaria dizer que a técnica é um sistema dentro da metodologia; primeiro porque metodologia aqui entendida pelo $\mathrm{PC}-1$ é diferente do 
conceito de metodologia adotado neste trabalho, conforme já foi definido por Borges (2010) em um momento oportuno; segundo porque o método e a técnica são distintos. A relação entre eles é estabelecida no momento em que a técnica auxilia e contribui para a execução de uma tarefa constituinte da sequência do método.

A maneira como o PC-1 expõe sua opinião sobre a técnica dá a impressão de que o método se divide em técnica, isto pode provocar a ideia de que ela seria uma ramificação do método, o que não é correto. Além disso, quando afirma que: "Para ensinar, podemos utilizar diferentes métodos, tomando como exemplo os sentidos visual, auditivo, sinestésico, usando todos ao mesmo tempo temos a técnica de ensino por meio da inteligência emocional", fica claro que ele realmente acredita que a técnica é um conjunto de métodos, pois afirma que os sentidos são métodos e a junção deles constitui a técnica. Nessa afirmação aparece a comprovação de que o termo técnica confunde-se com o método, mas, na verdade, a frase dita pelo PC-1 não constitui o conceito de técnica nem tampouco o de método.

Para o PC-2, conceituar o termo técnica é de grande dificuldade. Isso fica evidente no trecho abaixo:

PC-2: A palavra técnica me remete a pensar em abordagem tecnicista. Algo voltado para o professor tem o poder, os alunos recebem as informações e não tem o direito de pensar. Fogem das minhas explicações e entendimento. Contudo, posso dizer que a gramática pode ser uma técnica empregada em aulas de idiomas e ter esta conotação.

A concepção de técnica apresentada pelo PC-2 é um tanto confusa e como ele mesmo disse foge de seu entendimento, porém, mesmo não estando seguro para conceituá-la, deixa claro que, ao pensar em técnica, logo se remete à abordagem tecnicista $^{2}$, o que também foge da conceituação de técnica da qual estou tratando neste trabalho. Além disso, o PC-2 cita a gramática como um possível exemplo de técnica, mas ela não pode ser considerada uma técnica, pois a gramática não passa de uma explicação do sistema linguístico de uma língua.

Ao mesmo tempo em que para o PC-2 é difícil definir o termo técnica, para o PC-3 a técnica apresenta um significado bem amplo e, por isso, merece alguns esclarecimentos.

Note a concepção do PC-3 a respeito da técnica:

PC-3: Técnica é o que acontece em sala de aula, como cada atividade em sala será trabalhada para melhor aproveitamento do aluno, com uso de material visual, áudio, livro, quadro etc.

Nesse caso, dizer que a técnica é o que acontece em sala de aula não está tão longe do conceito proposto por Anthony (1963), mas the dar essa conotação torna-a muito abrangente e corre-se o risco de atribuir à técnica funções que ela não tem. Anthony (1963), ao definir a técnica, afirma que ela é a implementação, o que acontece em sala de aula, contudo, na sequência, o teórico esclarece que se trata de uma estratégia, um auxilio, ou seja, o autor delimita o significado de técnica após tratá-la como o que acontece em sala de aula. Em seguida, o PC-3 afirma que a técnica é a maneira como cada atividade é trabalhada, sendo que a própria atividade é uma técnica

\footnotetext{
2 Segundo Neubauer et al. (2007), essa tendência vê o aluno como um aprendiz por meio de estímulo e reforço, exigindo respostas prontas e corretas. Desse modo, o aluno torna-se condicionado e acrítico.
} 
e não a maneira como ela é realizada na prática. $\mathrm{O}$ que determina a maneira de conduzir a atividade será o método e como pano de fundo a abordagem, mas à técnica cabe o papel de artifício para obter o resultado esperado.

O professor-coordenador 3 apresentou uma concepção de técnica bem próxima de sua concepção real. No entanto, é preciso atentar-se para dois problemas encontrados em sua concepção: o primeiro é não defini-la como o que acontece na sala de aula, pois está sujeito a ampliar o sentido do termo; o segundo é não torná-la responsável por nortear as atividades usadas durante o ensino, já que cabe ao método planejar e definir as técnicas aplicadas em sala de aula.

A concepção apresentada pelo PC-4 coloca a técnica como a junção de vários métodos. Isso fica claro no excerto seguinte:

PC-4: Conjunto de métodos e processos. O profes sor escolhe os métodos para serem aplicados em sala de aula. Existem diferentes técnicas que podem ser usadas para ensinar inglês: jornal, revistas, DVD, música, etc.

O professor-coordenador 4 apresenta uma compreensão de técnica muito particular e diferente do que propõem os teóricos que sustentam este estudo. Segundo o PC-4, a técnica é um conjunto de métodos e processos. Após fazer essa afirmação, o próprio professor-coordenador confunde-se na definição de tal termo e acaba utilizando a palavra método para se referir à técnica, como fica claro no trecho: "O professor escolhe os métodos para serem aplicados em sala de aula. Existem diferentes técnicas que podem ser usadas para ensinar inglês: jornal, revistas, DVD, música etc.”. Além disso, define os recursos DVD, jornais, revistas etc. como técnicas. Atualmente, os recursos são vistos como materiais que auxiliam o ensino-aprendizagem, facilitando a compreensão do que foi explorado durante as aulas. De acordo com Almeida Filho (2011), a evolução das pesquisas na área de ensino-aprendizagem de língua estrangeira, fator responsável pela situação atual em que se encontra esse campo da ciência, não permite considerar como técnica qualquer tipo de recurso. Sendo assim, dizer que técnicas e recursos são sinônimos é uma afirmação conflituosa que gera confusões terminológicas como já foi constatado neste trabalho.

Por fim, analiso a concepção trazida pelo PC-5, na qual se nota um domínio maior do significado de técnica em relação aos demais participantes. Veja no trecho abaixo:

PC-5: A "técnica" seria uma atividade realizada durante a aula como parte da sequência do método (ex. uma information-gap-activity, utilizada no estágio "production" da aula para dar ao aluno a oportunidade de usar as áreas linguísticas apresentadas naquela aula, ou ainda uma sequência de "drills" feita durante o estágio "practice" para que o aluno consiga praticar aquelas áreas de maneira mais controlada antes de usá-la mais livremente no final da aula).

A concepção de técnica expressa na citação do PC-5 está de acordo com a conceituação de Anthony (1963). Segundo o PC-5, a técnica é uma atividade realizada durante a aula como parte da sequência do método. Essa noção mostra a função estratagema da técnica ao ser utilizada como um auxilio na execução de determinado método. A partir dos exemplos citados pelo PC-5, pode-se notar que a técnica funciona na prática como um meio de pôr em funcionamento aquilo que foi ensinado. Por esse motivo, é vista como um artifício para se alcançar o objetivo traçado pelo método. 


\section{Considerações finais}

Ao final da apresentação das concepções que envolvem os termos abordagem, método e técnica, fica evidente que ambos os termos ainda despertam uma grande confusão quanto à sua definição. Além disso, muitas vezes são usados um pelo outro sem que o usuário perceba que se trata de termos diferentes quanto à concepção. A princípio, acreditava-se que a confusão terminológica era fruto da falta de formação específica, contudo, após me deparar com os primeiros dados, evidenciei que mesmo o PC-2 tendo formação na área de Letras, não obteve sucesso ao conceituar os termos abordagem, método e técnica, assim como o PC-1 formado em processamento de dados e o PC-4 graduado em Cinema.

Além disso, os resultados revelam que a ausência de formação específica e a má formação apontam para uma situação conflituosa diante de problemas de origem pedagógica, uma vez que o professor-coordenador, desprovido de uma formação linguística e pedagógica consistente, dificilmente compreenderia a profundidade significativa e funcional desses termos, tampouco saberia lidar com questões de ensinoaprendizagem vivenciadas em institutos privados de idiomas, ou seja, tanto a prática docente como a coordenação pedagógica podem ser comprometidas pelo desconhecimento teórico acerca da pedagogia do ensino de línguas.

\section{REFERÊNCIAS}

ALMEIDA FILHO, J. C. P. de. A importância do artigo de Edward M. Anthony (1963) e da sua tradução hoje. Revista HELB, Rio de Janeiro, v.5, n.5, jan. 2011. Disponível em: <http $/ /$ www.helb.org.br>. Acesso em: 20 jun. 2014.

Dimensões Comunicativas no Ensino de Línguas. 7. ed. Campinas: Pontes, 2013. 113 p.

ANTHONY, E. M. Approach, Method and Technique. English language teaching, London, v.17, n.2, p. 63-67, fev. 1963.

BORGES, E. F. do V. Metodologia, Abordagem e pedagogia de ensino de línguas. Linguagem \& Ensino, Pelotas, v.13, n.2, p. 397-414, dez. 2010.

CELCE-MURCIA, M. Grammar Pedagogy in Second and Foreign Language Teaching. Tesol Quarterly, Los Angeles, v.25, n.3, p. 459-480, set. 1991.

HOLMES, J. What's my methodology? The ESPecialist, São Paulo, v.21, n.2, p. 127146, mar. 2000.

LEFFA, V. J. O ensino de línguas estrangeiras no contexto nacional. Contexturas, São Paulo, n.4, p. 13-24, mar. 1999.

NEUBAUER, A. et al. Um olhar sobre a trajetória da Educação: dos paradigmas conservadores ao paradigma emergente. Athena: Revista Científica de Educação, Curitiba, v.8, n.8, p. 55-71, jun. 2007.

NUNAN, D. Language Teaching Methodology: a textbook for teachers. Phoenix: ELT, 1995. $264 \mathrm{p}$.

RICHARDS, J. C. et al. Approaches and methods in language teaching. Cambridge: Cambridge University Press, 2001. 270 p. 
STAKE R. E. Case Studies. In: DENZIN, N. K. et al. (orgs.). Strategies of qualitative inquiry. Londres: SAGE Publications, 1998. p. 86-109.

Recebido em: 22/09/2015

Aprovado em: 05/03/2016

\section{ANEXO}

\section{Entrevista Escrita - Questionário}

1-Qual é a sua formação acadêmica? Em qual instituição realizou a graduação?

2-Você já realizou algum curso de pós-graduação, extensão, etc.? Qual (is)? Qual a carga horária do curso? Em qual instituição foi realizado?

3-Como você aprendeu inglês? Relate a sua trajetória como aprendiz de inglês.

4-Há quanto tempo você atua como professor de inglês? Por que escolheu trabalhar nessa área?

5-Há quanto tempo você trabalha como coordenador(a) de curso de inglês? Por que você acha que foi escolhido(a) para ocupar esse cargo?

6-Descreva o contexto de ensino-aprendizagem de língua inglesa no qual você trabalha.

7-Descreva a sua função como coordenador(a) na instituição na qual trabalha.

8-O Instituto de Idiomas no qual você trabalha oferece algum curso de formação para os professores da Unidade? Se sim, quem ministra esse curso? Qual a carga horária? Que assuntos são abordados no curso? Com que frequência esse curso é realizado?

9-O que você compreende por abordagem? Explique. Dê exemplos.

10-O que você compreende por método? Explique. Dê exemplos.

11-O que você compreende por técnica? Explique. Dê exemplos.

12-O Instituto no qual você atua como professor(a) e coordenador(a) se apoia em alguma abordagem/método/técnica específica(o) de ensino de inglês? Qual? Como são realizadas as aulas baseadas nessa abordagem/método/técnica?

13-Como o Instituto escolhe uma determinada abordagem/método/técnica? Quem é responsável por essa escolha?

14-Você conhece ou busca informações teóricas que deem suporte à prática em sala de aula? Exemplifique.

15-Segundo o site desse Instituto de Idiomas, o ensino é baseado em métodos e recursos de ponta com o objetivo de preparar os alunos para a comunicação real? Por que você acha que foi escolhida essa abordagem/método/técnica? Como ela (ele) é utilizada(o) em sala de aula?

16-Cite exemplos de uma aula que segue a proposta de ensino dessa instituição. 